\title{
Da Vinci's foot illustration and its errors
}

\author{
Didem Dönmez, Menekşe Karahan, Oğuz Taşkınalp \\ Department of Anatomy, School of Medicine, Trakya University, Edirne, Turkey
}

\begin{abstract}
Leonardo da Vinci is an important philosopher, astronomer, architect, engineer, inventor, mathematician, anatomist, musician, sculptor, writer and painter who lived in the Renaissance period. In addition to his skills in numerous diverse areas of study, he has important contributions to anatomy, cornerstone of medicine. Leonardo da Vinci performed many cadaver dissections. His anatomical illustartions are brilliant, despite the limitations of his time. However, a number of errors have been found in these illustrations. Here, we interpreted the illustration of da Vinci named "The anatomy of a foot".
\end{abstract}

Keywords: foot; illustration; Leonardo da Vinci

Anatomy 2018;12(3):155-157 (02018 Turkish Society of Anatomy and Clinical Anatomy (TSACA)

\section{Leonardo da Vinci's early years}

Da Vinci was born on 15 April 1452 in Mount Albano, Florence. He was the son of Sar Pierro da Vinci, a lawyer. Her mother was a peasant woman. Due to the requirements of that period, her parents never got married. Leonardo's father married to a noble woman and Leonardo had to live with his grandparents who raised him well. ${ }^{[1]}$

\section{Leonardo da Vinci's Interest in Anatomy}

Leonardo da Vinci's interest in anatomy began in Milan when he was working for Ludovico Maria Sforza. Da Vinci's favorite tools were sharp knives, chisels and bone saws. He had no assistant at that time. That's why he had to transcribe quickly his observation right after each dissection section. It is still not known how he preserved the cadavers. ${ }^{[2]}$ He performed approximately 30 cadaver dissections. ${ }^{[3]}$ After 1510 , he collaborated with a young professor named Marcantonio della Torre. Later on, with the advance of science, dissection studies increased. In this way, the accuracy of the teachings of the previous period began to be questioned, and it was then found that Leonardo da Vinci's work had some mistakes. ${ }^{[47]}$ For example, his work "The anatomy of a foot" is confusing like "Mona Lisa".

\section{"The Anatomy of a Foot"}

At a quick glance to the illustration, to the alignment of the metatarsal bones and phalanges, we can say this is the lateral side of the foot. Also, the phalanges are gradually becoming smaller. So, the illustrated tendons in this work probably belong to the peroneus brevis and peroneus longus muscles. In addition, the location of the nerve lying from the back of the leg to dorsum of the foot implies this is the superficial peroneal nerve. This nerve becomes superficial by penetrating the deep fascia in the junction between upper $2 / 3$ and lower $1 / 3$ of the posterior leg. It's divided into two branches at the dorsum of the foot: the dorsal medial cutaneous nerve and the dorsal intermedial cutaneous nerve. ${ }^{[8]}$ It's not possible to say this is the peroneus tertius muscle (Figure 1a), because the tendon of the peroneus tertius muscle passes under the extensor retinaculum.

However, there is another tendon in the drawing (marked in Figure 1a). This also refutes the idea of being the lateral side of the foot. If it's the medial side, it can be assumed that the tibialis posterior, flexor digitorum longus and flexor hallucis longus muscles are observed behind the medial malleolus. On the medial side, we should clearly see the extensor hallucis longus muscle with a thick tendon. Also, the structure with the question mark can be assumed as the great saphenous vein (Figure 1b). However, this structure goes to the posterior of the leg, and therefore, does not suit with the path of the great saphenous vein. It's not possible to say this is the tibialis anterior muscle, because the muscle 

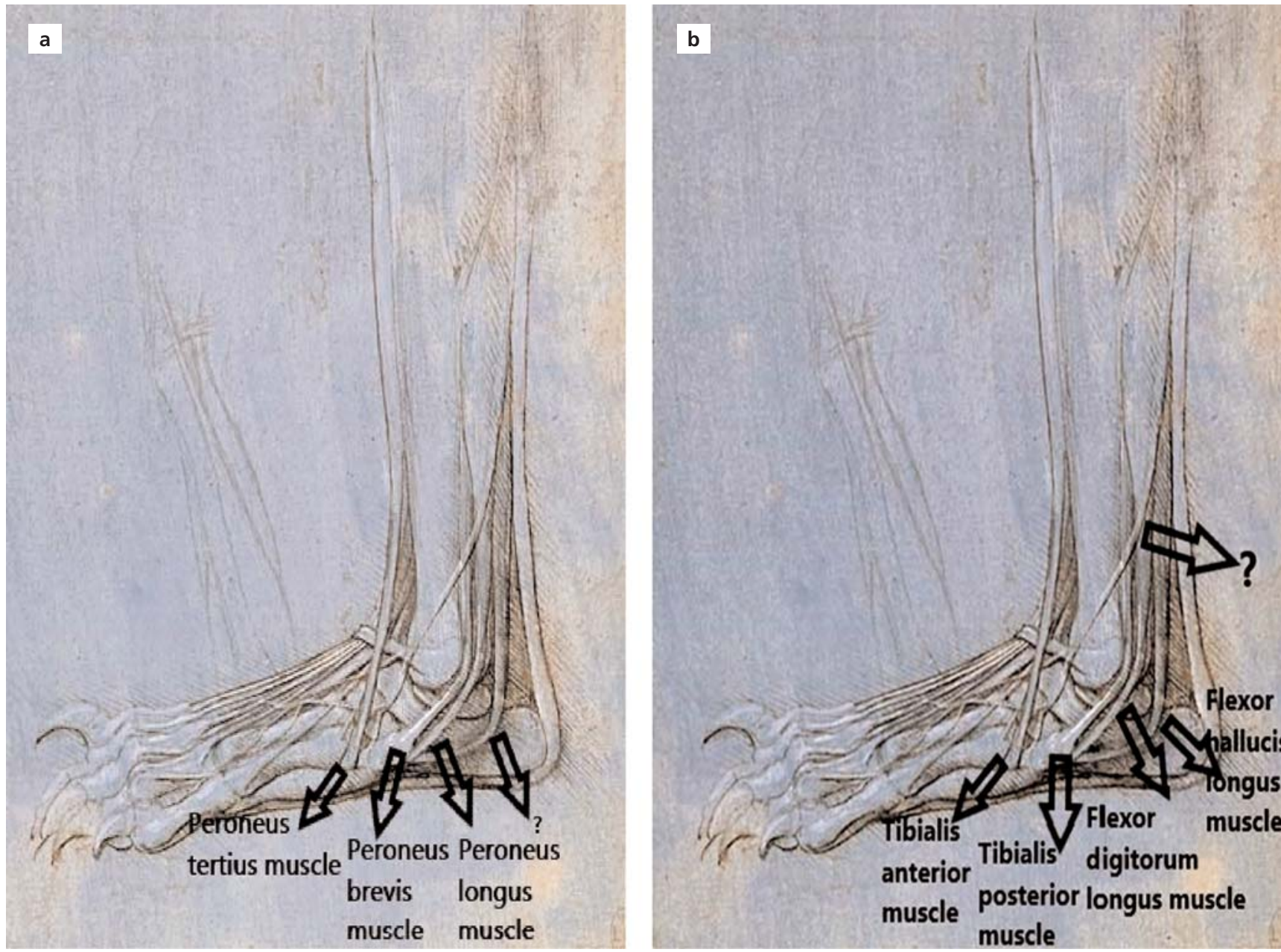

Figure 1. . Lateral (a) and medial (b) views of the human foot showing tendons which support the foot, respectively. ${ }^{[9]}[$ Color figure can be viewed in the online issue, which is available at www.anatomy.org.tr]

passes under the extensor retinaculum. So, we could not come to a decision on which side this may be.

Jastifer et al. ${ }^{[10]}$ examined another drawing of foot by Leonardo da Vinci. In this work, the anatomical structures supporting the medial arch of the foot are clearly seen. Compared to the work studied in this article, the two drawings look quite different from each other. The work we studied can be one of his early works. In this respect, this piece reminded us Mona Lisa's face.

\section{Conclusion}

Leonardo da Vinci has been influencing people for centuries with his magnificent intelligence. His anatomical work presented new details for the surgical treatment of previously unexplored areas. Therefore, surgeons and anatomists owe him as his works facilitated and improved their practice. We can understand his respect for his work from his words before his death: "I have offended God and mankind because my work did not reach the quality it should have". ${ }^{[1]}$

\section{References}

1. Jose AM. Anatomy and Leonardo da Vinci. Yale J Biol Med 2001;74: 185-95.

2. White M. Leonardo: the first scientist. London (UK): Little, Brown; 2001. 384 p.

3. Toledo-Pereyra LH. Leonardo da Vinci: the hidden father of modern anatomy. J Invest Surg 2002;15:247-9.

4. Bowen G, Gonzales J, Iwanaga J, Fisahn C, Loukas M, Oskouian RJ, Tubbs RS. Leonardo da Vinci (1452-1519) and his depictions of the human spine. Childs Nerv Syst 2017;33:2067-70.

5. Clayton M, Philo R. Leonardo da Vinci: anatomist. London (UK): Royal Collection Trust; 2012. 260 p.

6. O'Malley CD, Saunders JB de CM. Leonardo da Vinci on the human body: the anatomical, physiological, and embryological draw- 
ings of Leonardo da Vinci: with translations, emendations and a biographical introduction. New York (NY): Henry Schuman; 1952. $506 \mathrm{p}$.

7. Tubbs RI, Gonzales J, Iwanaga J, Loukas M, Oskouian RJ, Tubbs RS. The influence of ancient Greek thought on fifteenth century anatomy: Galenic influence and Leonardo da Vinci. Childs Nerv Syst 2018;34:1095-101.

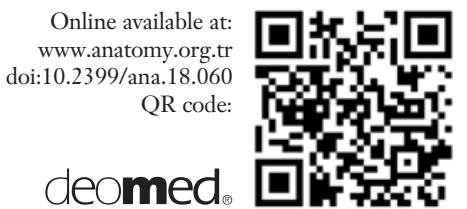

8. Garg K. Human anatomy: regional and applied dissection and clinical. New Delhi: CBS Publishers; 2010. 472 p.

9. The anatomy of a foot - by Leonardo da Vinci. [Internet].[Cited 2018 May 8]. Available from: [https://www.leonardodavinci.net/ theanatomy-of-a-foot].

10. Jastifer JR, Toledo-Pereyra LH. Leonardo da Vinci's foot: historical evidence of concept. J Invest Surg 2012;25:281-5.

\author{
Correspondence to: Didem Dönmez, MD \\ Department of Anatomy, School of Medicine, \\ Trakya University, Balkan Campus, 22040, Edirne, Turkey \\ Phone: +90 28423576 41/1510 \\ e-mail: didemdonmez@trakya.edu.tr \\ Conflict of interest statement: No conflicts declared.
}

This is an open access article distributed under the terms of the Creative Commons Attribution-NonCommercial-NoDerivs 3.0 Unported (CC BY-NCND3.0) Licence (http://creativecommons.org/licenses/by-nc-nd/3.0/) which permits unrestricted noncommercial use, distribution, and reproduction in any medium, provided the original work is properly cited. Please cite this article as: Dönmez D, Karahan M, Taşkınalp O. Da Vinci's foot illustration and its errors. Anatomy 2018;12(3):155-157. 